Unerfreulich an dem Band ist die Lektorierung. Für zahlreiche Tippfehler sowie unvollständige und übervollständige Sätze ist zwar der Verfasser in erster Linie verantwortlich, aber Herausgeber und Verlag haben ebenso für die formale Genauigkeit ihrer Manuskripte zu bürgen.

Abschließend ist festzuhalten, dass Bytzeks Buch sowohl politischen Praktikern als auch wissenschaftlich Interessierten unbedingt zur Lektüre zu empfehlen ist. Es untersucht systematisch ein bislang von der deutschen Wahlforschung stiefmütterlich behandeltes Phänomen, von dem der Alltags- wie der Medienwelt längst klar ist, dass es erhebliche politische Implikationen hat. Bytzek versteht es, Brücken zu sehr verschiedenen Öffentlichkeiten zu schlagen, indem sie einerseits äußerst sorgfältig ihr methodisches Vorgehen dokumentiert, andererseits ihre Ergebnisse so aufbereitet, dass der methodisch weniger gewandte Praktiker ihre Analyse mit Gewinn lesen und ihre Schlussfolgerungen nachvollziehen kann.

Kai-Uwe Schnapp

\title{
Komplettes Handbuch des Bayerischen Landtags 1918 bis 1933
}

\section{Lilla, Joachim (Bearbeiter): Der Bayerische Landtag 1918/1919 bis 1933. Wahlvorschläge- Zusammensetzung - Biographien (Materialien zur bayerischen Landesgeschichte, Band 21), Kommission für bayerische Landesgeschichte, München 2008, XLI, 618 Seiten, € 42,-.}

Nach einem Pontifikalamt konstituierte sich am 28. April 1933 der den Schein der Legalität nur notdürftig wahrende "gleichgeschaltete“ Bayerische Landtag. Der Plenarsaal in der Prannerstraße - im Krieg später zerstört - war mit Hakenkreuzfahnen und weißblauen Rautenfahnen ausstaffiert. Im Schnellverfahren verabschiedete der Landtag unter seinem neuen Präsidenten Hermann Esser, einem „alten Mitkämpfer Adolf Hitlers“, am folgenden Tag den Entwurf des „Gesetzes zur Behebung der Not des bayerischen Volkes und Staates“ durch Erheben von den Plätzen. Gegen das „Ermächtigungsgesetz“ stimmte wie zuvor im Reichstag nur die Sozialdemokratische Fraktion: Von den 17 Abgeordneten fehlte „unentschuldigt“ Michael Poeschke, der kurz zuvor „völlig verstört“ (Wilhelm Hoegner, S. 458) aus dem KZ Dachau entlassen worden war. Danach trat der Landtag nicht mehr zusammen. Am 13. November feierte die Nationalsozialistische Fraktion den parlamentarischen Kehraus. Die Sozialdemokraten, deren Mandate am 7. Juli „kassiert“ wurden, hatte der Landtagspräsident bereits am 23. Juni wissen lassen, dass er die zugeteilten Mandate „bis auf weiteres als erloschen“ (S. XXXVI) betrachtete. In Verbindung mit der Auflösung des Reichstags am 14. Oktober 1933 wurden die zuvor gleichgeschalteten „Volksvertretungen“ aufgelöst. 1949, drei Jahre nach dem Wiederbeginn des parlamentarischen Lebens, konnten der Bayerische Landtag und der Bayerische Senat in das renovierte Maximilianeum einziehen, das zu einem Synonym für das Landesparlament geworden ist.

Das Handbuch von Joachim Lilla ist mehr als ein biographisches Nachschlagewerk über die 654 Abgeordneten des Bayerischen Landtages zwischen der Revolution von 1918/19 und dem „Ende der Parteien“ in Deutschland 1933. Neben den Mandatsträgern widmet der Bearbeiter den 988 erfolglosen Wahlbewerbern sein Augenmerk. In der gebotenen Kürze referiert er das Wahlrecht, behandelt die Stimmkreiseinteilung und die bayerische Spezialität der Landesabgeordneten, die - als Instrument gegen die „Atomisierung des politischen Lebens" (Heinrich von Jan, S. XXXI) gepriesen - den im Landtag vertretenen Parteien 
bei der Verwertung der Reststimmen freie Hand bot. Erst infolge verschiedener Klagen und der Entscheidung des Bayerischen Staatsgerichtshofs erklärte der Landtag am 22. Oktober 1931 die 15 Mandate der Landesabgeordneten für ungültig. Die daraufhin beschlossene Wahlrechtsänderung wirkte sich aber nur noch für den am 24. April 1932 gewählten Landtag aus, in den die NSDAP mit 43 Mandaten nach der Bayerischen Volkspartei mit 45 Sitzen als zweitstärkste Fraktion einzog.

Für die Antiparlamentarier im Reichstag hat Lilla 2004 unter dem sprechenden Titel „Statisten in Uniform“ eine biographische Dokumentation vorgelegt. Zu den 94 Landtagsabgeordneten, die auch dem Reichstag angehörten - ohne Unterscheidung echter Doppelmandatare - zählen allein 38 Mitglieder des „Uniformierten Reichstags“, die nach 1945 keine politische Rolle mehr spielten: Neun waren bei Kriegsende bereits tot, unter ihnen der am 30. Juni 1934 ermordete Gregor Strasser. Julius Streicher wurde 1946 in Nürnberg hingerichtet. In insgesamt 13 Fällen lassen die Biographien Internierung, Haft und Entnazifizierungsstufen erkennen. Der Ausgang des Verfahrens (Euthanasie) gegen den Arzt Walter Schultze, vom Bundesgerichtshof an das Münchener Schwurgericht zurückverwiesen, wird nicht erwähnt.

Das Handbuch bietet fast alles, was ein Benutzer sich wünschen mag: die Wahlvorschläge, die durch einen Index der nichtgewählten Kandidaten und eine Übersicht der Wahlvorschläge nach Parteien ergänzt werden, Übersichten zur Zusammensetzung des Provisorischen Nationalrats und der Landtage (von den Ausschüssen abgesehen) und nicht zuletzt die „Biographische Dokumentation“. Nützlich sind die im Anhang präsentierten Übersichten zu den Landtagswahlen, zur Mitgliedschaft in anderen Parlamenten, das Verzeichnis der Staatsminister sowie der Staatsräte und Staatssekretäre. Und natürlich fehlen bei einem „Lilla“ Orts- und Personenregister nicht. Nur hinsichtlich einer ersten Auswertung des biographischen Materials hält sich der Bearbeiter zurück. So wäre es durch Verknüpfung mit dem Sprechregister möglich gewesen, das Bild des bayerischen Volksvertreters zu konturieren. Für die Figur des legendären Abgeordneten „Jozef Filser aus Mingharding, Bosd daselbst" war in der Dokumentation leider kein Platz. Diese Ehre widerfuhr an anderer Stelle immerhin dem nicht weniger legendären Legationsrat Edmund F. Dräcker. Weit mehr hätten Übersichten zur Verfolgung und Ausbürgerung nicht fehlen sollen. Gleichwohl verdient die vorliegende „Datenbasis“, innerhalb von „nur zwei Jahren fertiggestellt“, alle Anerkennung, die auch nicht dadurch eingeschränkt wird, dass immer noch mehr wünschbar ist. Ob die Schreibweise „Volksrechtpartei“ so falsch ist wie angenommen, sei dahingestellt, im Reichstag war sie jedenfalls gebräuchlich.

Es dürfte sich anbieten, eine solche Dokumentation online zu stellen und dafür Ergänzungen und Korrekturen im Einzelfall zu berücksichtigen sowie insbesondere die Materialien aus dem ehemaligen Berlin Document Center (BDC) - nun im Bundesarchiv - systematisch auszuwerten. Auch durch „genealogische“ Verweise - erinnert sei hier an Hans Troßmann, den ersten Direktor beim Deutschen Bundestag und Sohn des Landtags- und Reichstagsabgeordneten Karl Troßmann - könnte die beeindruckende Bilanz in einer zweiten (Online-)Auflage noch an Gewicht gewinnen. Aber vielleicht möchte sich der Bearbeiter zunächst einem vernachlässigten Feld zuwenden, das dringend beackert werden sollte: die hier nicht umfassend berücksichtigten Bundesversammlungen seit 1949. Wer, wenn nicht Joachim Lilla, könnte aus einem mausgrauen Verzeichnis endlich ein Handbuch machen. 